\title{
Antimicrobial Effect of Drug Incorporated Nanoparticles Against Oral Pathogens
}

\author{
GEORGETA ZEGAN ${ }^{1}$, MIHAELA MOSCU ${ }^{2 *}$, EDUARD RADU CERNEI ${ }^{1}$, ELENA MIHAELA CARAUSU ${ }^{3 *}$, \\ ALINA SODOR-BOTEZATU ${ }^{1}$ \\ ${ }^{1}$ Grigore T. Popa University of Medicine and Pharmacy, Faculty of Dental Medicine, Department of Surgery, 16 Universitatii \\ Str., 700115, Iasi, Romania \\ ${ }^{2}$ Grigore T. Popa University of Medicine and Pharmacy, Faculty of Medicine, Department of Morphological and Functional \\ Sciences 1, 16 Universitatii Str., 700115, Iasi, Romania \\ ${ }^{3}$ Grigore T. Popa University of Medicine and Pharmacy, Faculty of Dental Medicine, Department of Management and Public \\ Health, 16 Universitatii Str., 700115, Iasi, Romania
}

Last few years antibiotics resistance known a major problem that concerns the specialists in the dentistry field due to the improper usage of anti-infectious drugs. Administration of third generation quinolones, levofloxacin (Lev), in dental practice is preferred since has few nonhazardous adverse effects, is used once daily and can be successfully applied as intra-pocket films.This study investigated the possibility of preparing levofloxacin loaded layered double hydroxides nanoparticles in order to enhance antibiotic efficacy against oral pathogens. The nanoparticles obtained under optimal conditions were physico-chemically analyzed and intercalation efficiency was tested. The results of this work revealed that the use of these nanoparticles type levofloxacin loaded layered double hydroxides has the major advantage of prolonged release of the drug, thus allowing an increase of the period between administration and the diminution of side effects of the antibiotic. Further researches should focus on biocompatible properties and antibacterial effect as these nanomaterials supposed to be a sustainable drug delivery system.

Keywords: nanoparticles, drug carriers, antibacterial properties, public health dentistry, oral infections.

Effective management of dental infections is a worldwide challenge by eliminating the pathogen agents without altering the existing microbial ecology. Several approaches were developed to inhibit oral biofilm while avoiding commensals elimination from oral cavity. Oral infections are microbial and involve a combination of Gram (-), Gram (+), facultative anaerobes and certain anaerobic bacteria. Dentistry specialists prescribe medications for oral conditions management, especially oro-facial infections. Prescribing of antibiotics by dentists is an important issue of dental practice. Nowadays, fluoroquinolones offer a major efficacy, a better defense profile than their forerunners and a broader spectrum of antimicrobial action [1-4]. The promotion of levofloxacin occurred during a period when advantages were important in the fields of molecular biology, pharmacodinamics, toxicology, pharmacoepidemiology and drug resistance with consequences on the process of antibiotics research and development. In the last decades we witnessed notable growth in understanding biology mechanisms and drug side effects [5- 16].

Antibiotic delivery using layered double hydroxides (LDHs) type nanoparticles was extensively studied in last few years due to their efficiency of preserving drug active molecules into the interlayer gallery and slowly release at controlled rate in human cells. LDHs structure consists of positive charge counterbalancing exchangeable anions and water molecules. These nanostructures belong to the class of anionic clays where bivalent and trivalent metal cations occupy distributed octahedral through hydroxide anions present at the vertices to constitute the two-dimensional layers. General formula for LDHs is $\left[\mathrm{M}\left({ }_{1-x}\right)^{\mathrm{II}} \mathrm{M}_{\mathrm{x}}^{\mathrm{III}}(\mathrm{OH})_{2}\right]\left[\mathrm{A}^{\mathrm{n}-}\right]_{\mathrm{x} / \mathrm{n}^{\prime}} \cdot \mathrm{zH}_{2} \mathrm{O}$ where $\mathrm{M}^{\mathrm{II}}$ and $\mathrm{M}^{\mathrm{III}}$ represent metal cations, $\mathrm{A}^{\mathrm{n}-}$ charge compensating anions and $\mathrm{x}$ the mole fraction of $\mathrm{M}^{\mathrm{II}}$ and $\mathrm{M}^{\mathrm{III}}$ that are regularly structured [17-20]. Negatively charged antimicrobials, bioactive molecules and therapeutically active compounds can simply be exchanged with present interlayer anions and intercalated into the LDHs structure (figure 1) for prolonged release of drug in targeted areas of human body [21- 25].

*email: mihaela_moscu@ymail.com,mihaelacarausu@yahoo.com 
Herein, we report synthesis of levofloxacin intercalated MgAlLDHs delivery system by co-precipitation method. The obtained samples were characterized using FTIR, XRD and TG-DTA techniques. The release profile was determined using UV-VIS analyzer and the results revealed the capacity of MgAlLDHs nano-architectures in releasing levofloxacin in a sustained and controlled manner.

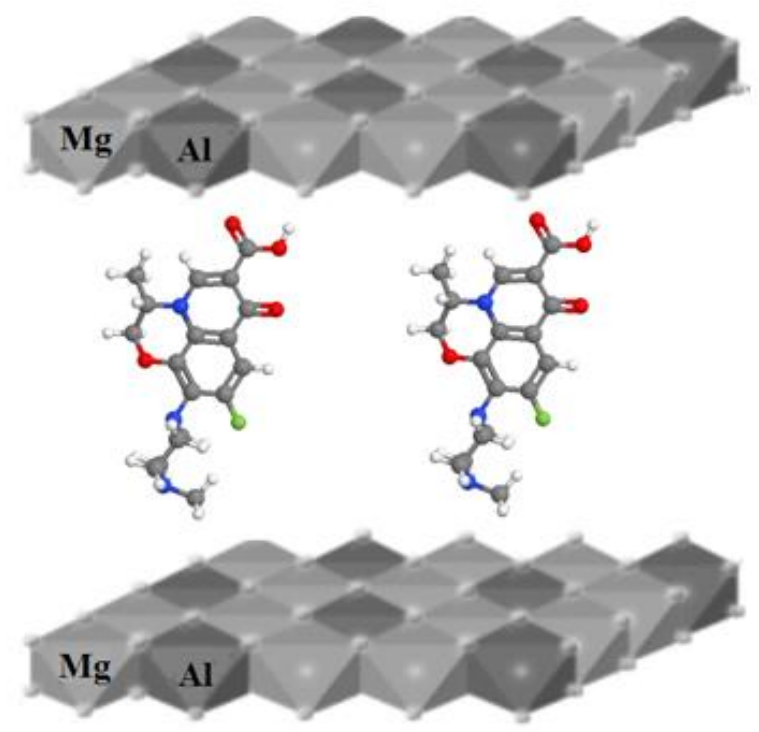

Fig.1.Schematic model for levofloxacin intercalated LDHs

\section{Experimental part}

Materials and methods

Preparation of MgAlLDHs

An aqueous solution containing precursor salts of $\mathrm{Mg}^{2+}$ and $\mathrm{Al}^{3+}$ with a molar ratio of 1:3 was prepared by dissolving metal salts in double distilled water. Additionally, a solution of $\mathrm{NaOH} 1 \mathrm{M}$ was added under nitrogen flow and vigorous stirring maintaining the $\mathrm{pH}$ at a constant value of 8.0. The obtained white precipitate was aged under stirring at $40^{\circ} \mathrm{C}$ for 24 hours then separated by centrifugation, washed with deionized water and dried at $40^{\circ} \mathrm{C}$ for 20 hours.

\section{Preparation of levofloxacin intercalated MgAlLDHs}

Levofloxacin intercalated MgAlLDHs (Lev-MgAlLDHs) was synthesized using co-precipitation method. Hence, 300 $\mathrm{ml}$ of aqueous solution containing metal salts and $200 \mathrm{ml}$ aqueous solution containing 0.02 mol levofloxacin were added drop wise together maintaining the $\mathrm{pH}$ value at 7.5 by adding $1 \mathrm{M} \mathrm{NaOH}$ solution. The obtained compound was aged under stirring for $36 \mathrm{~h}$. Then, the obtained precipitate was separated by centrifugation, washed intensively with deionized water and dried at $40^{\circ} \mathrm{C}$ for 24 hours.

\section{Results and discussions}

FTIR spectrum for free levofloxacin presented in figure 2 reveals the unique bands specific to this drug. The two bands present at 3420 and $3270 \mathrm{~cm}^{-1}$ indicate a stretch vibration of the $-\mathrm{OH}$ group. Bands appeared around $2930,2850 \mathrm{~cm}^{-1}$ frequencies are attributed to aliphatic $(\mathrm{C}-\mathrm{H})$ stretching vibration. Band at $1725 \mathrm{~cm}^{-1}$ is assigned to strong carbonic acidic group $(\mathrm{C}=\mathrm{O})$, while the band at $1620 \mathrm{~cm}^{-1}$ specifies the stretch of ketone. There is a structural stretching vibration due to benzene at 1530 and $1445 \mathrm{~cm}^{-1}$ frequencies and aromatic $(\mathrm{C}-\mathrm{H})$ flex at $800 \mathrm{~cm}^{-1}$ frequency.

FTIR spectrum for MgAlLDHs presented in figure 3 shows a number of specific bands to these nanoparticles. Thereby, the band at $3525 \mathrm{~cm}^{-1}$ is attributed to the $-\mathrm{OH}$ bond stretching vibration. The peculiar band around $1380 \mathrm{~cm}^{-1}$ is due to the nitrates group between the layers and the bands between 400 and $600 \mathrm{~cm}^{-1}$ are assigned to $\mathrm{Mg}-\mathrm{O}$ and $\mathrm{Al}-\mathrm{O}$ bonds. 
For levofloxacin-MgAlLDHs type nanostructure (figure 4), FTIR spectrum reveals that this compound present several bands indicates the certain intercalation of the drug between the layers. The occurrence of the two bands around 3480 and $3360 \mathrm{~cm}^{-1}$ indicates the stretching vibration of the $-\mathrm{OH}$ group. The band at $2895 \mathrm{~cm}^{-1}$ refers to the presence of C-H stretching vibration. The appearance of the band at $1670 \mathrm{~cm}^{-1}$ is attributed to $\mathrm{C}=\mathrm{O}$ bonds and presents a shift to the lower frequency. Stretching vibration of ketone is observed at $1590 \mathrm{~cm}^{-1}$ while the structural stretch of benzene is noticed at $1480 \mathrm{~cm}^{-1}$. The band around $1360 \mathrm{~cm}^{-1}$ belong to the stretching vibration of $\mathrm{NO}_{3}$ group and the band around $765 \mathrm{~cm}^{-1}$ states a C-H aromatic flex.

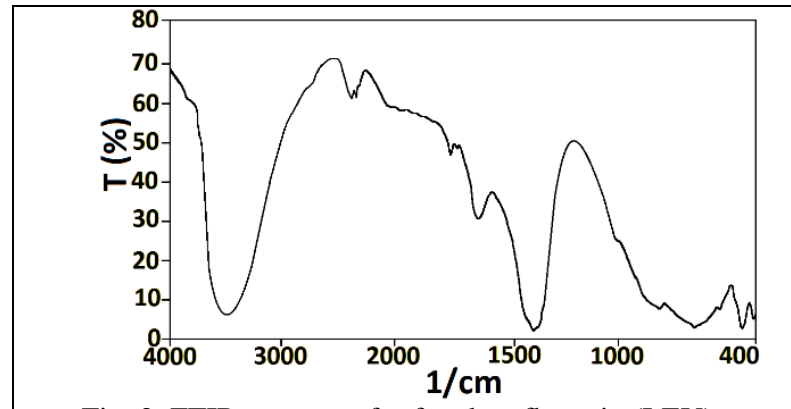

Fig. 2. FTIR spectrum for free levofloxacin (LEV)

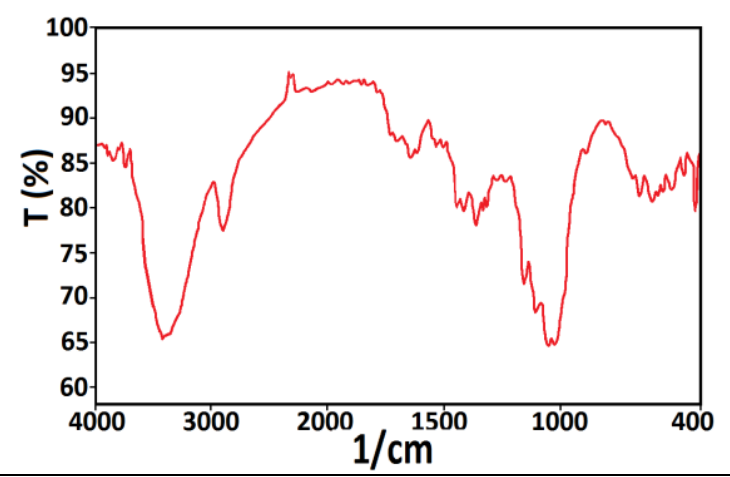

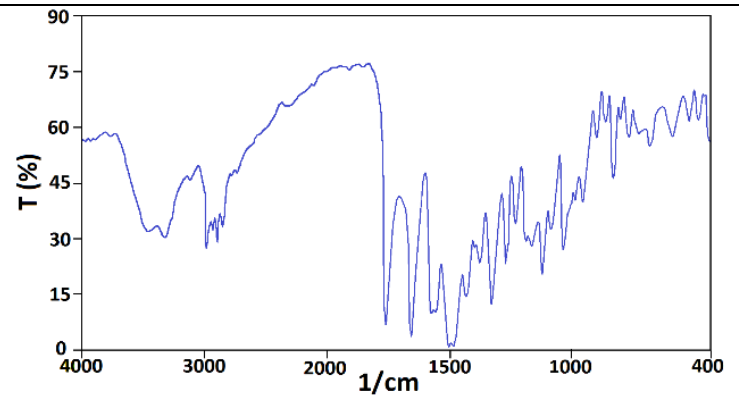

Fig. 3. FTIR spectrum for MgAlLDHs

Fig.4. FTIR spectrum for levofloxacin intercalated layered double hydroxides (LEV-MgAlLDH)

The XRD spectrum of MgAlLDHs and LEV-MgAlLDHs was studied to realize the differences in thickness of the layer before and after the antibiotic intercalation between layers by using the Brack's law.

Figure 5 presents the X-ray diffraction spectroscopy of MgAlLDHs, noticing the crystalline levels (003), (006) and (009). The level (003) occurs at the angle of $10.47^{\circ}$ with crystalline distance of $0.84 \mathrm{~nm}$. The level (006) shows up at $22.03^{\circ}$ with crystalline distance of $0.41 \mathrm{~nm}$, while the level (009) appears at $34.44^{\circ}$ with crystalline distance of $0.26 \mathrm{~nm}$.

By seeing the X-ray diffraction spectrum of the LEV-MgAlLDHs in Figure 6, the intercalation procedure seems to have been made. The level (003) emerges at approximately $2^{\circ}$ with a crystalline distance of $1.85 \mathrm{~nm}$, while the level $(006)$ at $9.7^{\circ}$ with crystalline distance of $0.92 \mathrm{~nm}$. The level (009) arises to intercede with the level (006) of the layered double hydroxides due to its proximity to the position, which cannot be distinct very clearly.

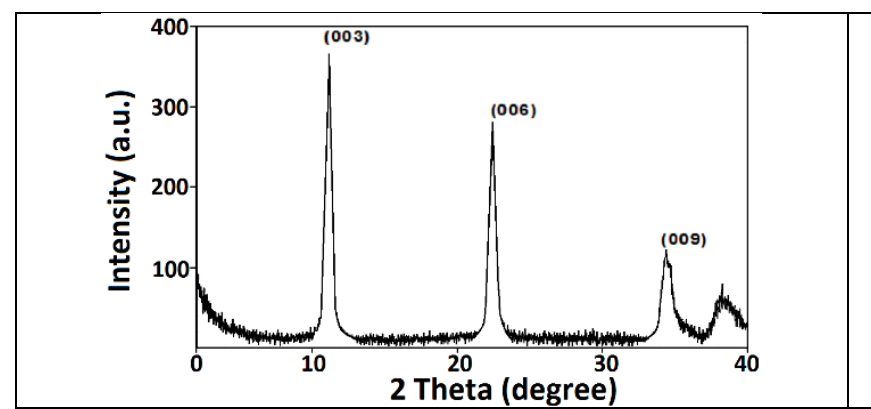

Fig. 5.XRD spectrum for the MgAlLDHs

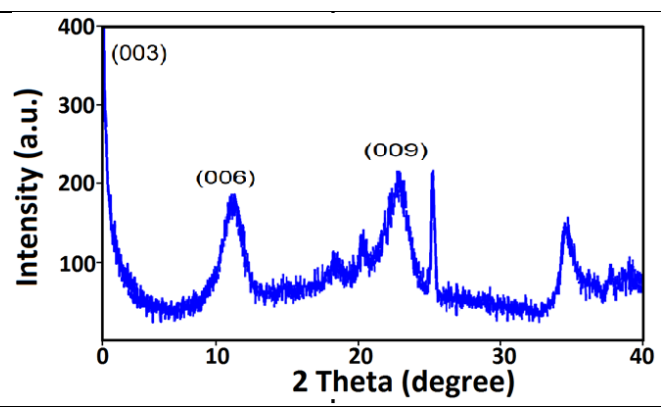

Fig. 6. XRD spectroscopy of LEV-MgAl LDH

Figure 7 shows thermo-gravimetric curves of the precursor and of the MgAlLDHs loaded with levofloxacin. The plot of the antibiotic could not be recorded because the compound degrades rapidly once the decomposition temperature is achieved.

As presented in figure 7, the first stages in the weight loss process happen in the temperature range of 50 to $130-150^{\circ} \mathrm{C}$ being assigned to the water from the interlayer gallery, which represents about 10 to $13 \%$ of the compound weight. 


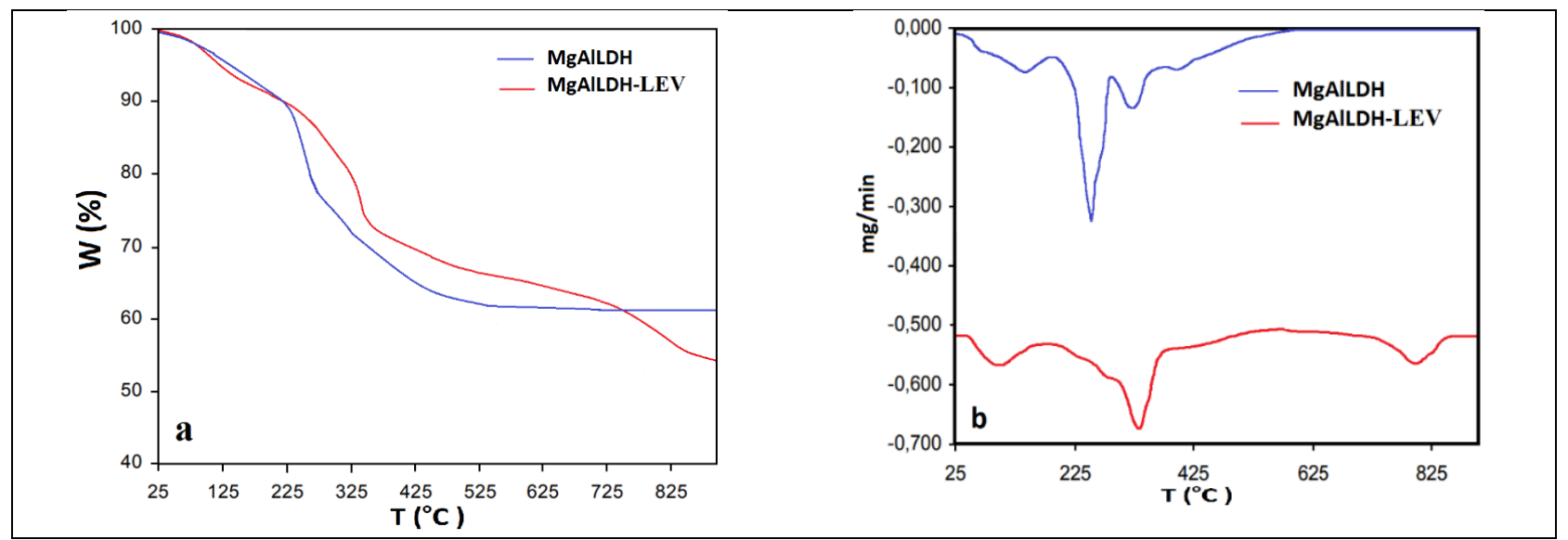

Fig. 7. TG and DTG curves for LEV-MgAlLDH

The next stages are attributed to weight losses between 5 and $25 \%$. The DTG curves presented in figure $7 \mathrm{~b}$ reveal a complex degradation occurs in multiple steps. The thermal degradation of MAlLDH-LEV indicates four stages. The biggest weight loss is registered in the temperature range of $300-500^{\circ} \mathrm{C}$; approximately $15 \%$ of the MgAlLDH-LEV. This weight loss stage is associated with the layersde-hydroxylation and the beginning of the levofloxacin decomposition. Taking into account the fact that the melting point of levofloxacin is $225^{\circ} \mathrm{C}$, the results reveal an increase in the thermal stability of the antibiotic after intercalation.

\section{Conclusions}

Levofloxacin present an excellent activity against Gram (-) bacilli being available as tablets, capsules and parenteral formulation for the bacterial infections therapy. Is an antibiotic rapidly and completely absorbed after administration and is preferred instead of other anti-infectious agent. Generaly is well tolerated but has some side effects such as vomiting, nausea, diarrhea, headache and dizziness. All these can be avoided if this drug is intercalated into hydrotalcites nanoparticles by releasing the drug gradually which decreases antibiotic side effects. Physicochemical properties of nanoparticles by FTIR, XRD and TG-DTA techniques were analyzed. The obtained results confirm that the use of levofloxacin loaded Layered double hydroxides nanoparticles can be successfully used for delivery of various antimicrobials offering an overview about modern nanomaterials based treatment strategies against oral infections.

\section{References}

1.NELSON, J.D., Pocket book of pediatric antimicrobial therapy, Williams and Wilkins, 1996.

2.Hersh, E.V., J Am Dent Assoc, 130(2), 1999, p. 236.

3.DAR-ODEH, N., RYALAT, S., SHAYYAB, M., ABU-HAMMAD, O., TherClin Risk Manag., 4(5), 2008 , p. 1111.

4.BENNET, P., BROWN, M., Clinical pharmacology, CHURCHILL LIVINGSTONE, 2003, p. 201.

5.LEWIS, M.A., Br Dent J. 205(10), p. 2008537.

6.LIU, H.H., DrugSaf, 33 (5), 2010, p. 353.

7.ADDY, M., MARTIN, M.V., Oral Dis.,9 (Suppl 1), 2003, p. 38.

8.STEIN, G.E., GOLDSTEIN, E.J., Anaerobe, 9(2), 2003, p. 75.

9.AVANI, R.P., SONENDER, P.S., SANTOSH, S.M., SAVITHA B.N., PRIYANKA, N., NITISH, K., SUKE, D.K., Journalof investigative and clinical dentistry, 6, 2015, p. 170 ..

10.PRIYANKA, M.B, YOGESH, S.C., SANKET, S.D., SURESH, D.K, KHUSHBUSHENGHANI, PANKIT, R.S., IJPRBS, 2 (3), p. 2013185.

11.LOUISE, C.S., JAYSHREE, D., PHILIP, A.C., JOHN, H., Journal of Antimicrobial Chemotherapy, 53, 2004 , p. 567.

12.OLARU, C., DIACONESCU, S., TRANDAFIR, L., GIMIGA, N., STEFANESCU, G., CIUBOTARIU, G., BURLEA, M., Gastroenterology Research and Practice, 2016, Article Number: 3989721.

13.NOVAC, O., BARBACARIU, L., SLANINA, A.M., FRASINARIU, O.E., TRANDAFIR, L.M., Medical-Surgical Journal-Revista MedicoChirurgicala, 122, 2018, p. 689

14.ANTON, D.T., TOCAN, L., DIACONU, G., TRANDAFIR, L.M., ILIESCU, M.L., Revista Romana de Bioetica, 12, no. 1, 2014 , p. 65.

15.TRANDAFIR, L.M., LEON, M.M., FRASINARIU, O., BACIU, G., DODI, G., COJOCARU, E., Journal of Clinical Medicine, 8, no. 7, 2019 , art. No. 1023.

15.TRANDAFIR, L.M., BACIU, G., CONSTANTIN, M.M.L., MASTALERU, A., TEMNEANU, O.R., MIHAI, B., NOVAC, O., FRASINARIU, O.E., IVAN, A., TUDORACHI, N.B., Rev. Chim. (Bucharest), 69, no. 11, 2019, p. 3048.

16.MIYATA, S., Clays Clay Miner. 23, 1975, p. 369.

17.CAVANI, F., TRIFIRO, F., VACCARI, A., Catal. Today, 11, 1991, p. 173.

18.KIDANE, A., BHATT, P.P., Curr. Opin. Chem. Biol., 9, 2005, p. 347.

19.KWAK, S.Y., KRIVEN, W.M., WALLING, M.A., CHOY, J.H., Biomaterials, 25, 2004, p. 5995. 
20.LI, W.Z., LU, J., CHEN, J.S., LI, G.D., JIANG, Y.S., LI, L.S., HUANG, B.Q., J. Chem. Technol. Biotechnol., 81, 2006 , p. 89. 21.MEYN, M., BENEKE, K., LAGALY, G., Inorg. Chem., 29, 1990, p. 5201.

22.PETRAK, K., Drug Discov. Today, 10, 2005, p. 1667.

23.FISCHBACH, M.A., WALSH, C.T., Science., 325(5944), 2009, p. 1089.

24.KEITH, C.T., BORISY, A.A., STOCKWELL, B.R., Nat. Rev. Drug Discov., 4(1), 2005, p. 71.

Manuscript received: 11.12.2019 